\title{
Utilization of Hysterectomy Following Chemoradiation for IB2/IIA2 Cervical Cancer in the National Cancer Data Base
}

\author{
WAQAR HAQUE $^{1}$, VIVEK VERMA $^{2}$, E. BRIAN BUTLER ${ }^{1}$ and BIN S. TEH ${ }^{1}$ \\ ${ }^{1}$ Department of Radiation Oncology, Houston Methodist Hospital, Houston, TX, U.S.A.; \\ ${ }^{2}$ Department of Radiation Oncology, Allegheny General Hospital, Pittsburgh, PA, U.S.A.
}

\begin{abstract}
Background/Aim: Performing hysterectomy following chemoradiotherapy (CRT) for IB2/IIA2 cervical cancer is highly controversial. This study evaluated national practice patterns in utilization of post-CRT hysterectomy in the United States compared to CRT alone, as well as outcomes. Materials and Methods: The National Cancer Database was queried for patients with newly diagnosed IB2/IIA2 cervical cancer. Multivariable logistic regression analysis assessing factors predictive of undergoing post-CRT hysterectomy. Kaplan-Meier analysis evaluated overall survival (OS) and Cox proportional hazards modeling determined variables associated with OS. Results: Altogether, 1,691 patients met the inclusion criteria; 1,551 (92\%) received CRT alone, and 140 (8\%) underwent subsequent hysterectomy. Patients with tumors $\geq 8 \mathrm{~cm}$ were more likely to undergo hysterectomy. Patients who underwent additional hysterectomy, likely a higher-risk cohort, displayed OS comparable to those receiving CRT alone. Conclusion: Greater tumor size was associated with hysterectomy following CRT for IB2/IIA2 cervical cancer in the United States. These patients achieve OS comparable to those receiving standard-of-care CRT.
\end{abstract}

IB2/IIA2 cervical cancer represents larger-volume disease without clinical evidence of parametrial spread; its category 1 treatment is concurrent chemoradiotherapy (CRT) (1). This is, in part, owing to phase III data for IB/IIA tumors showing no differences in survival with surgery over radiotherapy alone (2). However, that trial has limited contemporary applicability for many reasons. Firstly, the proportion of patients without bulky disease may have diluted the effect of

Correspondence to: Waqar Haque, MD, Department of Radiation Oncology, Houston Methodist Hospital, Cancer Center and Research Institute, Houston, TX 77094, U.S.A. Tel: +1 7134414800, Fax: +1 7134414493, e-mail: waqarh786@gmail.com

Key Words: Cervical cancer, radiation therapy, chemotherapy, hysterectomy. surgical debulking. Secondly, the lack of magnetic resonance imaging (MRI) and positron emission tomography/computed tomography (PET/CT) workup was likely associated with a higher rate of occult parametrial involvement, for which surgery has no modern role (2). Thirdly, antiquated surgical and radiation techniques led to high rates of morbidity, especially in patients receiving multimodality therapy. Fourthly, chemotherapy use at the time was nonstandard.

Surgical therapy for these cases has several theoretical advantages. Firstly, if performed up-front, it allows for nodal sampling and thus promotes more refined selection of patients for adjuvant therapy, thereby reducing rates of over- and undertreatment. Secondly, it allows access to disease that may be difficult to (safely) address with brachytherapy. Thirdly, and most notably, the benefit of surgery may be in removing residual disease in patients with bulky tumors that are less likely to respond to definitive CRT. General oncological principles from numerous other types of neoplasms demonstrate the increased value of surgical excision for patients with larger, bulkier disease. It has been established that the efficacy of CRT is inversely proportional to the volume of disease present (3), and that there is a subset of patients for whom CRT will not be adequate to control the sheer volume of tumor. From a phase III trial of bulky stage IB cases, nearly half the patients receiving CRT had residual disease in the adjuvant hysterectomy specimen (4). Even in cases of complete clinical/radiological response to CRT, an estimated 30\% harbor pathological disease (5). Hence, administering further local therapy for these patients may eradicate suspected residual disease, which is a poor prognostic factor owing to the risk of metastatic seeding or becoming resistant to further CRT, among other reasons (6-8).

Although performing hysterectomy has been associated with improved pelvic control rates, there is little evidence to date showing survival benefits (9). A randomized trial suggested proportionally higher improvement for those with bulkier tumors, despite the lack of chemotherapy therein (10). This issue remains unresolved to date, and as such, surgical therapy is listed as an option for IB2/IIA2 disease by the National Comprehensive Cancer Network (1). The goal of this study 
was to evaluate national practice patterns in management of IB2/IIA2 cervical cancer with respect to utilization of hysterectomy following CRT, along with outcomes.

\section{Materials and Methods}

This investigation analyzed the National Cancer Data Base (NCDB), which is a joint project of the Commission on Cancer $(\mathrm{CoC})$ of the American College of Surgeons and the American Cancer Society, which consists of de-identified information regarding tumor characteristics, patient demographics, and patient survival for approximately $70 \%$ of the US population (11). The NCDB contains information not included in the Surveillance, Epidemiology, and End Results database, including details regarding use of systemic therapy and radiation dose. The data used in this study were derived from a de-identified NCDB file. The American College of Surgeons and the $\mathrm{CoC}$ have not verified and are not responsible for the analytic or statistical methodology employed nor the conclusions drawn from these data by the investigators. As all patient information in the NCDB database is de-identified, this study was exempt from Institutional Review Board evaluation.

Inclusion criteria for this study were age $\geq 18$ years with newlydiagnosed IB2/IIA2 N0 M0 cervical cancer diagnosed between 2004 and 2013. Patients were required to have received definitive concurrent CRT, defined as radiation therapy and chemotherapy initiated within 15 days of one another. Patients having undergone hysterectomy within 6 months after CRT were included and were classified as patients having undergone post-CRT hysterectomy; patients undergoing hysterectomy prior to CRT were excluded from analysis.

Information collected on each patient broadly included demographic data, comorbidity information, clinicopathological tumor parameters, and treatment facility characteristics. All statistical tests were two-sided, with a threshold of $p<0.05$ for statistical significance, and were performed using STATA (version 14; StataCorp; College Station, TX, USA). Fisher's exact or Chi-square test were used to analyze categorical proportions between groups in the non-parametric and parametric settings, respectively. Multivariable logistic regression modeling was utilized to determine characteristics that were predictive for surgical-based treatment. The Kaplan-Meier method was used for survival analysis; comparisons between the two cohorts were performed with the log-rank test. Overall survival (OS) was defined as the interval between the date of diagnosis and the date of death, otherwise patients were censored at last contact. Patients with an unknown vital status were excluded from the survival analysis. Univariate analysis was performed to determine which factors were associated with OS, and subsequently Cox multivariate analysis was performed including variables that were either significant or showed a strong trend to statistical significance on univariate analysis. Patients with unreported income or unrecorded distance from the treating facility were excluded from multivariate logistic regression and univariate analysis for survival due to their low numbers.

\section{Results}

In total, 1,691 patients met the study criteria (Table I). Of these, 1,551 (92\%) received CRT alone, and $140(8 \%)$ underwent subsequent hysterectomy. The majority of patients had IB2 disease and tumors $<8 \mathrm{~cm}$. Temporal trends for use of surgery were relatively stable over time.
Table I. Baseline characteristics of patients with cervical cancer.

\begin{tabular}{|c|c|c|c|}
\hline Characteristic & $\begin{array}{c}\text { CRT alone } \\
(\mathrm{n}=1551), \mathrm{n}(\%)\end{array}$ & $\begin{array}{l}\text { CRT + hysterectomy } \\
(\mathrm{n}=140), \mathrm{n}(\%)\end{array}$ & $p$-Value \\
\hline \multicolumn{4}{|l|}{ Age (years) } \\
\hline $30-44$ & $648(41.8 \%)$ & $77(55.0 \%)$ & 0.003 \\
\hline $45-59$ & $556(35.9 \%)$ & $46(32.9 \%)$ & \\
\hline$\geq 60$ & $347(22.4 \%)$ & $17(12.1 \%)$ & \\
\hline \multicolumn{4}{|l|}{ Race } \\
\hline White & $1129(72.8 \%)$ & $107(76.4 \%)$ & 0.621 \\
\hline African American & $305(19.7 \%)$ & $23(16.4 \%)$ & \\
\hline Other/not recorded & $117(7.5 \%)$ & $10(7.1 \%)$ & \\
\hline \multicolumn{4}{|l|}{ T-Stage } \\
\hline IB2 & $1062(68.5 \%)$ & $114(81.4 \%)$ & 0.001 \\
\hline IIA2 & $489(31.5 \%)$ & $26(18.6 \%)$ & \\
\hline \multicolumn{4}{|l|}{ Tumor size } \\
\hline$<6 \mathrm{~cm}$ & $660(42.6 \%)$ & $49(35.0 \%)$ & 0.154 \\
\hline $6-7.9 \mathrm{~cm}$ & $478(30.8 \%)$ & $42(30.0 \%)$ & \\
\hline$\geq 8 \mathrm{~cm}$ & $241(15.5 \%)$ & $30(21.4 \%)$ & \\
\hline Not reported & $172(11.1 \%)$ & $19(13.6 \%)$ & \\
\hline \multicolumn{4}{|l|}{ Charlson Deyo Score } \\
\hline 0 & $1367(88.1 \%)$ & $125(89.3 \%)$ & 0.745 \\
\hline 1 & $146(9.4 \%)$ & $13(9.3 \%)$ & \\
\hline$\geq 2$ & $38(2.5 \%)$ & $2(1.4 \%)$ & \\
\hline \multicolumn{4}{|l|}{ Facility type } \\
\hline \multicolumn{4}{|l|}{ Community Cancer } \\
\hline Program & $94(6.1 \%)$ & $9(6.4 \%)$ & 0.225 \\
\hline \multicolumn{4}{|l|}{ Comprehensive } \\
\hline \multicolumn{4}{|l|}{ Community Cancer } \\
\hline Program & $429(27.7 \%)$ & $33(23.6 \%)$ & \\
\hline \multicolumn{4}{|l|}{ Academic/ } \\
\hline Research Program & $553(35.7 \%)$ & $42(30.0 \%)$ & \\
\hline \multicolumn{4}{|l|}{ Integrated Network } \\
\hline Cancer Program & $57(3.7 \%)$ & $6(4.3 \%)$ & \\
\hline Other/not specified & $418(27.0 \%)$ & $50(35.7 \%)$ & \\
\hline \multicolumn{4}{|l|}{ Income } \\
\hline$\leq \$ 62999$ & $1229(79.2 \%)$ & $102(72.9 \%)$ & 0.210 \\
\hline$\$ 63000+$ & $305(19.7 \%)$ & $36(25.7 \%)$ & \\
\hline Not recorded & $17(1.1 \%)$ & $2(1.4 \%)$ & \\
\hline \multicolumn{4}{|l|}{ Year of diagnosis } \\
\hline $2004-2008$ & $423(27.3 \%)$ & $32(22.9 \%)$ & 0.259 \\
\hline 2009-2013 & $1128(72.7 \%)$ & $108(77.1 \%)$ & \\
\hline \multicolumn{4}{|l|}{ Payer status } \\
\hline Medicaid & $412(26.6 \%)$ & $36(25.7 \%)$ & 0.152 \\
\hline Medicare & $249(16.1 \%)$ & $12(8.6 \%)$ & \\
\hline Private & $609(39.3 \%)$ & $66(47.1 \%)$ & \\
\hline Uninsured & $217(14.0 \%)$ & $20(14.3 \%)$ & \\
\hline Other & $64(4.1 \%)$ & $6(4.3 \%)$ & \\
\hline \multicolumn{4}{|l|}{ Distance to center } \\
\hline$<25$ Miles & $1089(70.2 \%)$ & $98(70.0 \%)$ & 0.428 \\
\hline 25-100 Miles & $378(24.4 \%)$ & $30(21.4 \%)$ & \\
\hline >100 Miles & $68(4.4 \%)$ & $10(7.1 \%)$ & \\
\hline Not reported & $16(1.0 \%)$ & $2(1.4 \%)$ & \\
\hline
\end{tabular}

CRT: Chemoradiotherapy.

Multivariable logistic regression demonstrated that age $\geq 60$ years $(p=0.053)$ and stage IIA2 disease $(p=0.013)$ were independently associated with decreased likelihood of undergoing hysterectomy. There were trends towards increasing 
a

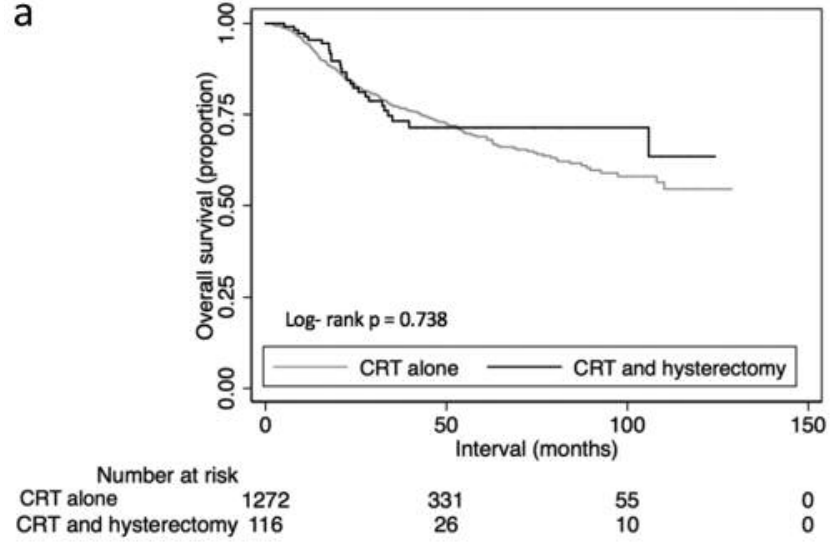

b

$12.00 \%$

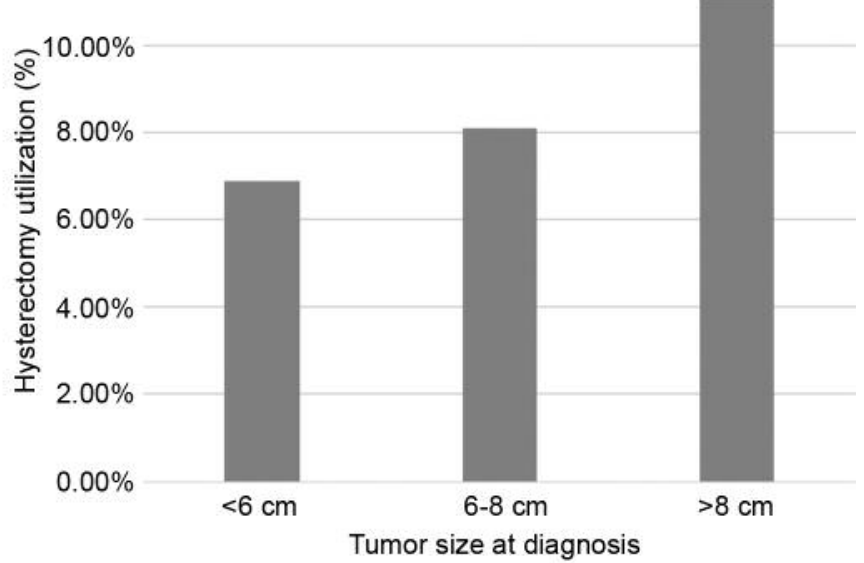

Figure 1. A: Kaplan-Meier curve comparing overall survival by therapy amongst all patients. B: Utilization of hysterectomy by tumor size. CRT: Chemoradiotherapy.

utilization of hysterectomy in patients residing farther from the treating facility $(p=0.070)$ and in those with higher income $(p=0.098)$. Notably, tumor size was also independently correlated with undergoing hysterectomy, as patients with tumors $8 \mathrm{~cm}$ or larger were more likely to undergo surgery (Figure 1B), 11.1\% of these patients doing so post-CRT.

In all patients, receipt of trimodality therapy was associated with OS comparable to that of the CRT cohort (Figure 1A). Although median OS was not reached, the mean OS was 94 months [95\% confidence interval $(\mathrm{CI})=84-104$ months] versus 91 months (95\% CI=87-94 months), respectively. The corresponding 5-year OS rates were $71 \%$ versus $69 \%(p=0.774)$. When substratifying patients by tumor size, there were no statistical differences in OS between cohorts $(<6 \mathrm{~cm}, 6-7.9 \mathrm{~cm}$, and $\geq 8 \mathrm{~cm}: p=0.251$, $p=0.292, p=0.828$, respectively).

Univariate analysis to assess predictors of OS confirmed that additional hysterectomy was not significantly associated with outcomes (Table II). Poorer OS was linked with advancing age, increasing comorbidities, and tumors $\geq 8 \mathrm{~cm}$ in size $(p<0.05$ for all $)$.

\section{Discussion}

Performing hysterectomy following CRT for IB2/IIA2 cervical cancer remains controversial, and is underutilized in the United States. This analysis of a large, contemporary national database, the first of its kind to date as far as we are aware, shows that several factors are associated with hysterectomy following concurrent CRT for IB2/IIA2 cervical cancer, such as age, stage, income status, and proximity to the treating institution. Tumor size was also a notable factor, with hysterectomy more likely to be performed in patients with larger initial volumes of gross disease. Despite the higher-risk nature of the trimodality group, these patients experienced OS comparable to those to treated with CRT alone.

Although it has been shown that income status is a predictor of undergoing surgery $(12,13)$, our study found there was also a trend for the use of hysterectomy amongst patients living further from the treating center. This may imply that clinicians may elect to offer hysterectomy to patients at risk of following up less frequently or being lost to follow-up. There may therefore be an implicit sense of doubt at achieving meaningful salvage therapy if disease progresses without careful surveillance, and therefore these patients may be offered up-front hysterectomy.

A major limitation of this analysis was the impossibility of determining whether patients treated with trimodality therapy underwent hysterectomy for adjuvant or salvage purposes. The present study used a cut-off period of hysterectomy within 6 months of completion of CRT in order to be included in the post-CRT hysterectomy cohort. Although various time frame cut-offs can be theoretically utilized, there is undoubtedly a 'gray area' during which patients may be followed-up for evaluation, and if disease is not found to regress, an 'early salvage' type of management may be elected, which hybridizes elements of adjuvant and salvage therapy. The finding of comparable OS between groups implies that the high-risk population treated with trimodality therapy may experience similar OS to the lowerrisk cases that underwent standard-of-care CRT alone, and may indirectly point to the efficacy of performing both CRT and adjuvant hysterectomy for poorly-responding disease. 
Table II. Univariate and multivariate analysis of factors predictive of overall survival for all patients.

\begin{tabular}{|c|c|c|c|c|c|c|}
\hline \multirow[b]{2}{*}{ Characteristic } & \multicolumn{3}{|c|}{ Univariate analysis } & \multicolumn{3}{|c|}{ Multivariate analysis } \\
\hline & Hazard ratio & 95\% Confidence interval & $p$-Value & Hazard ratio & 95\% Confidence interval & $p$-Value \\
\hline \multicolumn{7}{|l|}{ Group } \\
\hline Chemoradiation alone & 1 (reference) & & & - & - & - \\
\hline Chemoradiation and hysterectomy & 0.935 & $0.631-1.386$ & 0.738 & - & - & - \\
\hline \multicolumn{7}{|l|}{ Age (years) } \\
\hline $30-44$ & 1 (reference) & & & 1 (reference) & & \\
\hline $45-59$ & 0.979 & $0.757-1.265$ & 0.868 & 0.986 & $0.762-1.276$ & 0.917 \\
\hline$\geq 60$ & 1.632 & $1.260-2.113$ & $<0.001$ & 1.511 & $1.156-1.976$ & 0.003 \\
\hline \multicolumn{7}{|l|}{ Race } \\
\hline White & 1 (reference) & & & - & - & - \\
\hline African American & 1.170 & $0.903-1.515$ & 0.235 & - & - & - \\
\hline Other/not recorded & 0.744 & $0.467-1.187$ & 0.215 & - & - & - \\
\hline \multicolumn{7}{|l|}{ T-Stage } \\
\hline IB2 & 1 (reference) & & & - & - & - \\
\hline IIA2 & 1.066 & $0.853-1.333$ & 0.572 & - & - & - \\
\hline \multicolumn{7}{|l|}{ Tumor size } \\
\hline$<6 \mathrm{~cm}$ & 1 (reference) & & & 1 (reference) & & \\
\hline $6-7.9 \mathrm{~cm}$ & 1.104 & $0.857-1.423$ & 0.444 & 1.187 & $0.918-1.534$ & 0.191 \\
\hline$\geq 8 \mathrm{~cm}$ & 1.457 & $1.094-1.941$ & 0.010 & 1.498 & $1.123-1.998$ & 0.006 \\
\hline Not reported & 0.983 & $0.639-1.512$ & 0.938 & 0.983 & $0.638-1.513$ & 0.937 \\
\hline \multicolumn{7}{|l|}{ Charlson Deyo Score } \\
\hline 0 & 1 (reference) & & & 1 (reference) & & \\
\hline 1 & 1.410 & $1.019-1.950$ & 0.038 & 1.333 & $0.960-1.851$ & 0.086 \\
\hline$\geq 2$ & 3.776 & $2.369-6.018$ & $<0.001$ & 3.284 & $2.036-5.295$ & $<0.001$ \\
\hline \multicolumn{7}{|l|}{ Facility type } \\
\hline Community Cancer Program & 1 (reference) & & & - & - & - \\
\hline \multicolumn{7}{|l|}{ Comprehensive Community } \\
\hline Cancer Program & 1.355 & $0.857-2.143$ & 0.193 & - & - & - \\
\hline Academic/Research Program & 0.900 & $0.570-1.422$ & 0.651 & - & - & - \\
\hline Integrated Network Cancer Program & 0.854 & $0.414-1.762$ & 0.669 & - & - & - \\
\hline Other/not specified & 0.922 & $0.577-1.475$ & 0.736 & - & - & - \\
\hline \multicolumn{7}{|l|}{ Income } \\
\hline$\leq \$ 62999$ & 1 (reference) & & & - & - & - \\
\hline$\$ 63000+$ & 0.756 & $0.564-1.014$ & 0.062 & - & - & - \\
\hline \multicolumn{7}{|l|}{ Distance to center } \\
\hline$<25$ Miles & 1 (reference) & & & - & - & - \\
\hline 25-100 Miles & 1.157 & $0907-1.476$ & 0.241 & - & - & - \\
\hline$>100$ Miles & 1.002 & $0.603-1.664$ & 0.995 & - & - & - \\
\hline
\end{tabular}

The OS findings herein are similar to those of other studies (14-16) but are also clearly biased. There were imbalances between groups in terms of disease volume as well as distance from the facility, which may suggest a selection bias for the surgical arm due to the greater frequency of patients more likely to fail due to initial tumor size. Moreover, it is possible that certain salvage cases had occult metastasis, thus affecting prognosis. The OS findings must also be considered in light of the fact that the NCDB does not carry information on cancerspecific survival, and thus the oncological efficacy of postCRT hysterectomy cannot be firmly assessed with any database. Further data, ideally prospective, should expand on these and other results.

Although the NCDB provides a unique platform with which to study this important clinical question, limitations cannot go unmentioned. Firstly, NCDB investigations are inherently retrospective and can never eliminate selection biases, including reasons for post-CRT hysterectomy (or qualitative/quantitative tumor response) and nature of followup management. Secondly, this study also did not evaluate radiotherapy doses and whether patients received brachytherapy as part of the CRT regimen, owing to the further reduction in sample sizes in doing so. Thirdly, 
although the NCDB encompasses roughly $70 \%$ of the US population, only $\mathrm{CoC}$-accredited centers contribute data. Thus, the findings may not necessarily be representative of the entire US and international population.

\section{Conclusion}

Performing hysterectomy following CRT for IB2/IIA2 cervical cancer remains controversial, and is underutilized in the United States. This analysis of a large, contemporary national database, the first of its kind to date, shows that several factors are associated with hysterectomy following concurrent CRT for IB2/IIA2 cervical cancer, such as age, stage, income status, and proximity to the treating institution. Size was also a notable factor, with hysterectomy more likely to be performed in patients with a larger initial volumes of gross disease. Despite the higher-risk nature of the trimodality group, these patients experienced comparable OS to those treated with CRT alone.

\section{Conflicts of Interest}

There was no funding for this study. This study has not been presented or published in part or full form elsewhere. All Authors declare no conflicts of interest in regard to this study.

\section{References}

1 National Comprehensive Cancer Network. Cervical Cancer. Version 1.2018. https://www.nccn.org/professionals/physician_ gls/pdf/cervical.pdf Accessed January 14, 2018.

2 Landoni F, Maneo A, Colombo A, Placa F, Milani R, Perego P, Favini G, Ferri L and Mangioni C: Randomised study of radical surgery versus radiotherapy for stage Ib-IIa cervical cancer. Lancet 350: 535-540, 1987.

3 Hall EJ and Giaccia AJ: Radiobiology for the Radiologist. Lippincott Williams \& Wilkins; 2006.

4 Keys HM, Bundy BN, Stehman FB, Muderspach LI, Chafe WE, Suggs CL, Walker JL and Gersell D: Cisplatin, radiation, and adjuvant hysterectomy compared with radiation and adjuvant hysterectomy for bulky stage IB cervical carcinoma. N Engl J Med 340: 1154-1161, 1999.

5 Favero G, Pierobon J, Genta ML, Araujo MP, Miglino G, Del Carmen Pilar Diz M, de Andrade Carvalho H, Fukushima JT, Baracat EC and Carvalho JP: Laparoscopic extrafascial hysterectomy (completion surgery) after primary chemoradiation in patients with locally advanced cervical cancer: technical aspects and operative outcomes. Int J Gynecol Cancer 24: 608614, 2014.

6 Ferrandina G, Legge F, Fagotti A, Fanfani F, Distefano M, Morganti A, Cellini N and Scambia G: Preoperative concomitant chemoradiotherapy in locally advanced cervical cancer: safety, outcome, and prognostic measures. Gynecol Oncol 107(Suppl 1): S127-132, 2007.
7 Huquet F, Cojocariu OM, Levy P, Lefranc JP, Darai E, Jannet D, Ansquer Y, Lhuillier PE, Benifla JL, Seince N and Touboul E: Preoperative concurrent radiation therapy and chemotherapy for bulky stage IB2, IIA, and IIB carcinoma of the uterine cervix with proximal parametrial invasion. Int J Radiat Oncol Biol Phys 72: 1508-1515, 2008.

8 Touboul C, Uzan C, Mauguen A, Gouy S, Rey A, Pautier P, Lhomme C, Duvillard P, Haie-Meder C and Morice P: Prognostic factors and morbidities after completion surgery in patients undergoing initial chemoradiation therapy for locally advanced cervical cancer. Oncologist 15: 405-415, 2010.

9 Yang J, Shen K, Wang J, Yang J and Cao D: Extrafascial hysterectomy after concurrent chemoradiotherapy in locally advanced cervical adenocarcinoma. J Gynecol Oncol 27: e40, 2016.

10 Keys HM, Bundy BN, Stehman FB, Okagaki T, Gallup DG, Burnett AF, ROtman MZ, Fowlder WC Jr., Gynecologic Oncology Group: Radiation therapy with and without extrafascial hysterectomy for bulky stage IB cervical carcinoma: a randomized trial of the Gynecologic Oncology Group. Gynecol Oncol 89: 343-353, 2003

11 Bilimoria K, Stewart A, Winchester D and Yo CY: The National Cancer Data Base: a powerful initiative to improve cancer care in the United States. Ann Surg Oncol 15: 683-690, 2008.

12 Hoehn RS, Hanseman DJ, Jernigan PL, WIma K, Ertel AE, Abbott DE and Shah SA: Disparities in care for patients with curable hepatocellular carcinoma. HPB (Oxford) 17: 747-752, 2015.

13 Gabriel E, Thirunavukarasu P, Al-Sukhni E, Atwood K, and Nurkin SJ: National disparities in minimally invasive surgery for rectal cancer. Surg Endosc 30: 1060-1067, 2016.

14 Morice P, Rouanet P, Rey A, Romestaing P, Houvenaeghel G, Boulanger JC, Leveque J, Cowen D, Mathevet P, Malhaire JP, Magnin G, Fondrinier E, Berille $\mathrm{J}$ and Haie-Meder C: Results of the GYNECO 02 study, an FNCLCC phase III trial comparing hysterectomy with no hysterectomy in patients with a (clinical and radiological) complete response after chemoradiation therapy for stage IB2 or II cervical cancer. Oncologist 17: 6471, 2012.

15 Cetina L, González-Enciso A, Cantú D, Coronel J, PerezMontiel D, Hinojosa J, Serrano A, Rivera L, Poitevin A, Mota A, Trejo E, Montalvo G, Munoz D, Robles-Flores J, de la Garza J, Chanona J, Jimenez-Lima R, Wegman T and Duenas-Gonzalez A: Brachytherapy versus radical hysterectomy after external beam chemoradiation with gemcitabine plus cisplatin: a randomized, phase III study in IB2-IIB cervical cancer patients. Ann Oncol 24: 2043-2047, 2013.

16 Kokka F, Bryant A, Brockbank E, Powell M and Oram D: Hysterectomy with radiotherapy or chemotherapy or both for women with locally advanced cervical cancer. Cochrane Database Syst Rev 4: CD010260, 2015.

Received March 14, 2018

Revised April 17, 2018

Accepted April 18, 2018 